\title{
Comparison of T-Type Converter and NPC for the Wind Turbine Based on Doubly-Fed Induction Generator
}

\author{
Altan Gencer
}

\begin{abstract}
A three-phase T-type converter topology proposes for wind turbine based on doubly fed induction generator (DFIG). The proposed converter consists of only twelve power switches without flying capacitors or any clamping diodes. The proposed system is implemented to grid side converter of wind turbine. Fuzzy logic controllers are more widely used in wind turbines compared to traditional control systems. Fuzzy logic PI controller has been applied to $T$-type and the conventional neutral-point clamped (NPC) converters control circuits. Total harmonic distortion (THD) value of current of presented system is measured as $1.76 \%$. Also, DC-link voltage utilization can be maintained. Comparisons are conducted with T-type converter and a 3L-NPC) method under same operation conditions. The proposed scheme has been carried out to verify in simulation results.
\end{abstract}

Index Terms - T-type converter topology, doubly fed induction generator, wind turbine.

\section{INTRODUCTION}

$\mathrm{I}^{\mathrm{r}}$ RECENT YEARS, wind turbines have gained considerable importance among renewable energy sources. The various types of generators are used in wind turbines such as doubly-fed induction generator (DFIG), squirrel-cage induction generator (SCIG), and permanent magnet synchronous generator (PMSG). DFIG is the most widely used of these generator types. DFIG cannot be connected directly to the grid system. The DFIG needs to the converters in order to connect to the grid system. [1,2] The converter is made in various types. The two level three phase converters (traditional type) are used quite a lot in wind turbine. Traditional type converters have very simple structure and control system. On the other hand, the energy quality of traditional converters is low and they are not used for high voltage values. For this reason, multi-level converters have started to be applied for wind turbines in recent years [3].

ALTAN GENCER, is with Department of Electrical Engineering University of Nevsehir Hacı Bektaş Veli University, Nevşehir, Turkey,(e-mail: altangencer@nevsehir.edu.tr).

(iD https://orcid.org/0000-0002-5592-4070

Manuscript received November 16, 2020; accepted February 06, 2021. DOI: $\underline{10.17694 / \text { bajece. } 826624}$
The high number of switches in multi-level inverter is a disadvantage. On another hand, multi-level converters have superior features compared to conventional converters. It can be used in applications that require high power and voltage. In addition to, it has a great advantage in terms of energy quality. Also, switching losses are low due to the fact that they operate at low switching frequency [4].

Three-level converter topologies are two types which name as Neutral-Point Clamped (3L-NPC) and T-type. 3L-NPC consists of 12 switching and 6 diodes. T-type consists of 12 switching elements. At the same time, T-type are not required high voltage and current diodes. T-type has a simpler structure than 3L-NPC, it is cheap, and it produces energy quality [4-7].

In this study, a three-phase 3-level T-type converter is proposed for wind turbines based on DFIG. Fuzzy logic PI controller has been applied to the control system of the proposed converter. Fuzzy logic controllers obtain more effective results in complex systems compared to conventional control systems. THD values of current and voltage at the output of both converters systems have been measured under same operation conditions. The THD value of the proposed system is lower 3L-NPC converter. High harmonic causes distortions in the system and decreases efficiency. The proposed system are used less electronic components compared to 3L-NPC. Therefore, the proposed system reduces the switching losses and the cost of the system. The efficiency of proposed converter type has been proven by compared to 3LNPC converters.

The organization of this paper is as given: dynamic model of the wind turbine is expressed in Sec. 2. Proposed model is expressed in Sec. 3. T-type converter is explained in Sec. 4. Then, simulation results are explained in Sec. 5. The conclusion is given in Sec. 6 .

\section{DyNAMic Model OF Wind TURBINE}

The wind turbine system consists of a generator, blade, electronic converters, filter, and control system. A generator converts from a mechanical power to an electrical power. A wind turbines converts from wind power to electrical power. The electrical energy generated by a generator is not suitable for connecting directly to the electrical grid system. Therefore, converters are used to connect a wind turbine to electrical grid system. The converters regulate the generated voltage of the generator by means of control systems. 


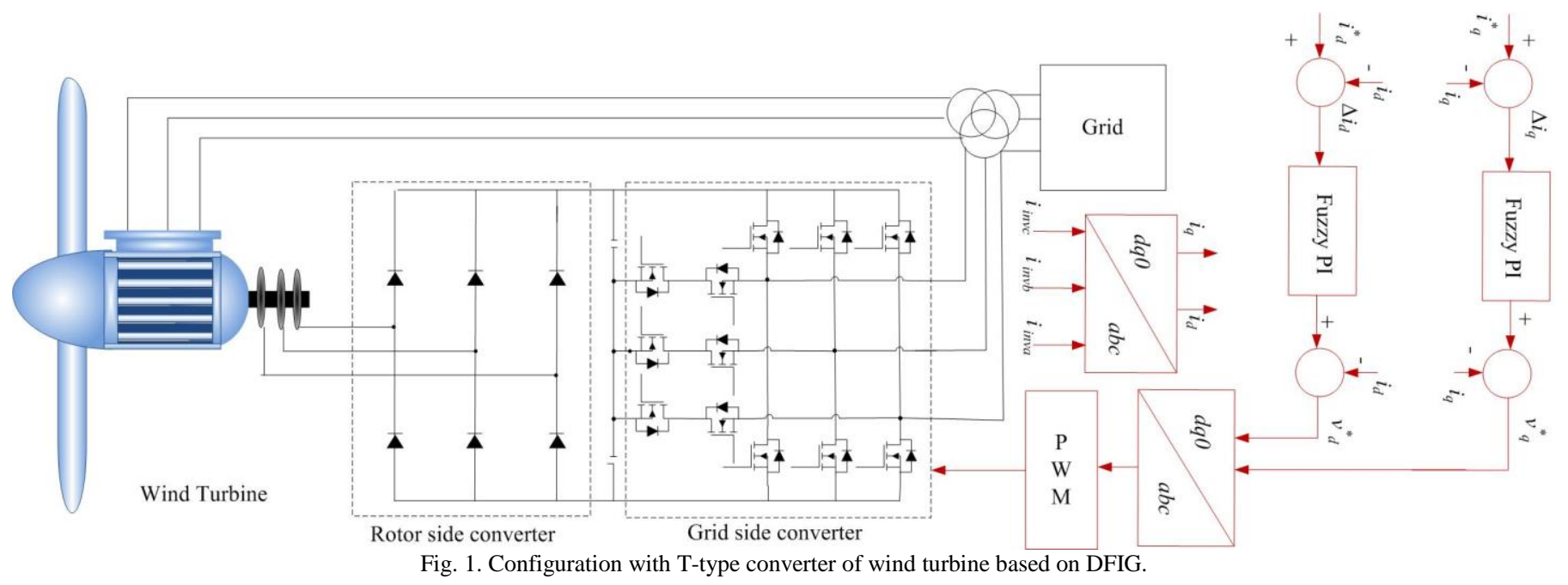

\section{A. Wind Turbine}

Wind turbines; It can be defined as mechanical systems that convert kinetic energy present in the wind into mechanical energy. The wind turbine cannot capture all the wind energy. For this reason, a mechanical power obtains from the wind turbine and is is given in Eq. 1 [8].

$$
P_{m}=\frac{1}{2} \rho A C_{p}(\lambda, \beta) v^{3}
$$

Where, the swept area of the rotor blades depicts $A, \rho$ represents the air density, the power conversion coefficient depicts $C_{p}$, the wind speed represents $v$. In this equation, if the swept area, air density and wind speed are taken as constant, aerodynamic power is obtained by the power factor of the wind turbine. $\lambda$ represents a ratio between an angular velocity of a wind turbine and a wind speed. This ratio is expressed as the type speed ratio and is given in Eq. 2 [8]

$$
\lambda=\frac{\omega_{m} R}{v}
$$

\section{B. Mathematical model of DFIG}

The mathematical model of DFIG is explained to simulate the whole system which consists of the stator and rotor. Several losses of DFIG are neglected such as hysteresis, magnetic saturation, stator, and rotor core losses. This model is the most widely accepted mathematical model of DFIG [1, 2].

$$
\begin{gathered}
v_{s}=R_{s} i_{s}+\frac{d \psi_{s}}{d t}+j \omega_{e} \psi_{s} \\
v_{r}=R_{r} i_{r}+\frac{d \psi_{r}}{d t}+j\left(\omega_{e}-\omega_{r}\right) \psi_{r}
\end{gathered}
$$

The flux components of rotor and stator are expressed by:

$$
\begin{aligned}
& \psi_{s}=L_{s} i_{s}+L_{m} i_{r} \\
& \psi_{r}=L_{r} i_{r}+L_{m} i_{s}
\end{aligned}
$$

\section{THE PROPOSED MODEL}

The proposed model for DFIG based on T-type converter is illustrated in Fig. 1. Proposed system consists of the wind turbine, power electronic converters, and controller. The rotor side converter consists of a three-phase full-wave uncontrolled rectifier. Grid side converter consists of T-type converter. Grid and rotor side converters are used to supply the electrical energy produced by the double feed induction generator to the grid. The 2-level converter has a simple operating principle. Total harmonic distortion (THD) value of conventional converter is higher than multi-level converters, while the 2level converter has a simple operating principle. Therefore, a three-phase T-type converter is built for the grid side converter of wind turbine system in this study. Grid and rotor side converters are used to supply the electrical energy generated by the double feed induction generator. The grid and rotor side controllers are designed to correct the electrical energy produced in the generator to meet the requirements of the load [9-19]. The three-phase T-type converter is given in Fig. 1.

In this study, a rotor and grid side converters were used to connect the wind turbine to the grid. Rotor side converter consists of three phase uncontrolled rectifier circuit. Rotor side converter converts 3-phase $\mathrm{AC}$ voltages generated by the double fed induction generator into DC voltage. A grid side converter converts from DC voltage to 3-phase AC voltage and provides it to be connected to the network. In this study, NPC and T type 3-phase converter types are applied for grid side converter. Fuzzy logic PI controller has been applied to these two converters control circuits. Fuzzy logic PI controller is more widely used in wind turbines compared to traditional control systems. Conventional control systems do not give effective results in varying operating conditions because its parameters are fixed. In this study, fuzzy logic PI controller block diagram applied to the controller of grid side converter and is given in Fig 2.a. In Fig. 2.b., the fuzzy logic PI controller consists of an input and an output. The error of the current value is read as an analog input from an input value of a fuzzy logic controller. A fuzzification is the process of transforming this analog input into fuzzy sets with some degree of membership. The input sets of the fuzzy controller 
BALKAN JOURNAL OF ELECTRICAL \& COMPUTER ENGINEERING, $\quad$ Vol. 9, No. 2, April 2021

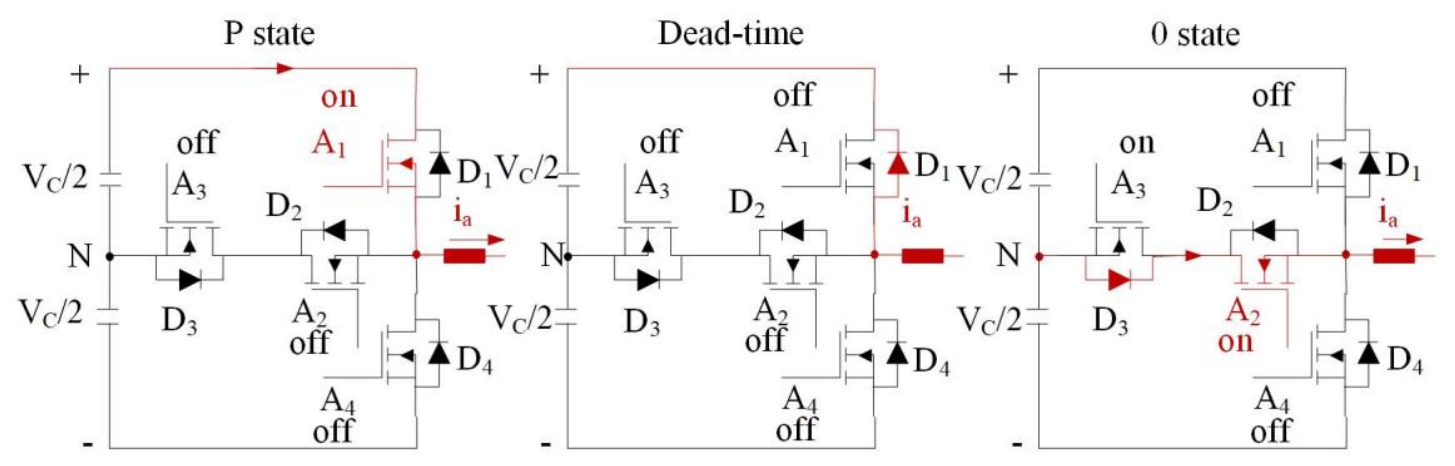

(a)

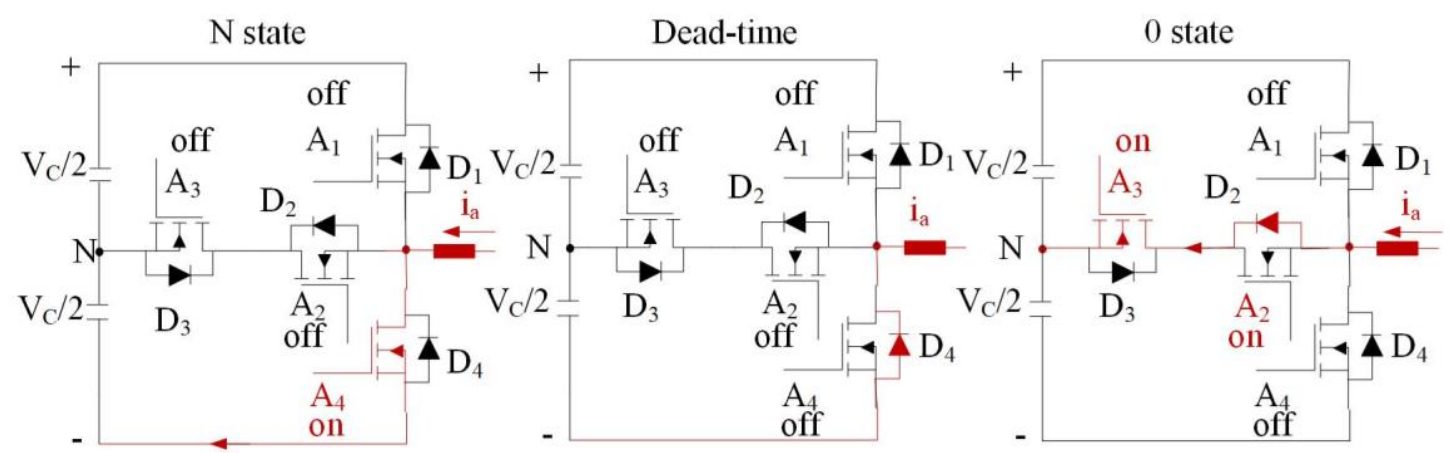

(b)

Fig.3. Current commutation during switching transition a) positive output current b) negative output current $[5,14,15]$.

are divided into seven sections consisting of triangular and trapezoid shaped curves. These seven variables are called Positive Small (PS), Positive Medium (PM), Positive Large (PB) Zero (Z), Negative Large (NB), Negative Medium (NM), and Negative Small (NS). In this study, the output sets of the fuzzy controller are divided into seven sections consisting of triangular and trapezoidal shaped curves. Defuzzification converts a fuzzy truth values to continuous output variable [2, 10, 11, 12, 13]. The defuzzification is expressed by:

$$
y=\frac{\sum_{i=1}^{m} y_{i}+\mu_{i}\left(y_{i}\right)}{\sum_{i=1}^{m} \mu_{i}}
$$

Where, $\mu_{\mathrm{i}}\left(y_{i}\right)$ depicts the membership function, $m$ represents the output quantificational index, $y_{i}$ represents the output variable, $y$ is the defuzzified output. $[2,10,11]$.

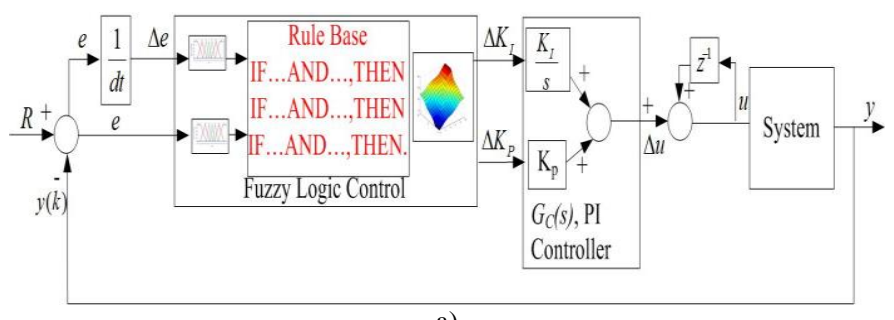

a)

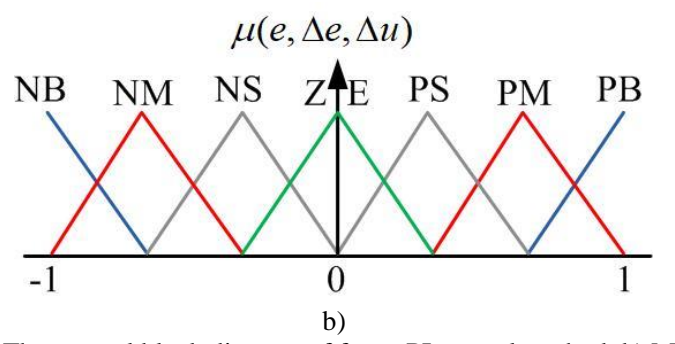

Fig.2. a)The general block diagram of fuzzy PI control method. b) MFs of e, $\Delta \mathrm{e}$, and $\Delta \mathrm{u}[2,10,11]$.

\section{T-TYPE CONVERTER}

A three level T-type converter method is illustrated in Fig. 3. The switching states of T-type converter are illustrated in Table I [5, 14-19]. The switching states are the negative $(\mathrm{N})$, neutral (0), and the positive (P) of dc-link voltage level. Three voltage levels of phase-neutral voltage are obtained by these switching states. The T-type method uses the same switch signals of the three-level NPC method modulation. A simple delay between switching on and off is applied to avoid a short circuit in a DC link [14-16].

TABLE I. Switching States [5, 14, 15, 16]

\begin{tabular}{|l|l|l|l|l|}
\hline State & Q1 & Q2 & Q3 & Q4 \\
\hline P & 1 & 1 & 0 & 0 \\
\hline 0 & 0 & 1 & 1 & 0 \\
\hline N & 0 & 0 & 1 & 1 \\
\hline
\end{tabular}

The current flows towards the AC terminal when the output voltage is positive. As seen in Fig. 3. a. [5, 14-16], the current flows from $V_{D C}(+)$ via $A_{1}$ to output terminal when $A_{1}$ 
switches on. A simple delay between switching on and off is applied to avoid a short circuit in a DC link. A simple delay time is $1 \mathrm{~ms}$ and all switches are off during this time. The current commutates to the inner switches $A_{2} / D_{3}$ when $A_{1}$ is switched off. The current flows from $\mathrm{N}$ via $\mathrm{D}_{3}$ and $\mathrm{A}_{2}$ to output terminal. $[15,16]$.

The current flows towards the $\mathrm{V}_{\mathrm{DC}}(-)$ when the output voltage is negative. As seen in Fig. 3. b. [5, 14-16], the current flows from output terminal to $\mathrm{V}_{\mathrm{DC}}(-)$ via $\mathrm{A}_{4}$ when $\mathrm{A}_{4}$ switches on. A simple delay between switching on and off is applied to avoid a short circuit in a DC link. A simple delay time is $1 \mathrm{~ms}$ and all switches are off during this time. The current commutates to the inner switches $\mathrm{A}_{3} / \mathrm{D}_{2}$ when $\mathrm{A}_{4}$ is switched off. The current flows from output terminal via $A_{3}$ and $D_{2}$ to N. $[15,16]$.

A 3L-NPC phase leg consists of 10 semiconductors which are 2 two diodes, 4 IGBTs, and 4 antiparallel free-wheeling diodes, while T-type phase leg composed of 8 semiconductors. The difference between NPC and T-type method is not only the number of power electronics. To achieve the same current THD value as $3 \mathrm{~L}$ topology, switching frequency is reduced, resulting in reduced switching power losses $[15,16]$.

\section{Simulation Results}

Both the proposed and NPC systems are implemented to the wind turbine which has the same power and control structures. The presented system is built-in Matlab / Simulink. Simulation parameters are applied to simulation time $2 \mu$ s and active power of wind turbine are 9MW. The switching signals required for the semiconductors are generated with priority in the Simulink study. The switching signals of a phase leg are illustrated in Fig. 4. T-type topology uses same switching signals of three-level NPC topology. The switching signals are obtained by comparing the reference sinusoidal wave with the triangular carriers. Also, switching signals are derived by means of control systems.
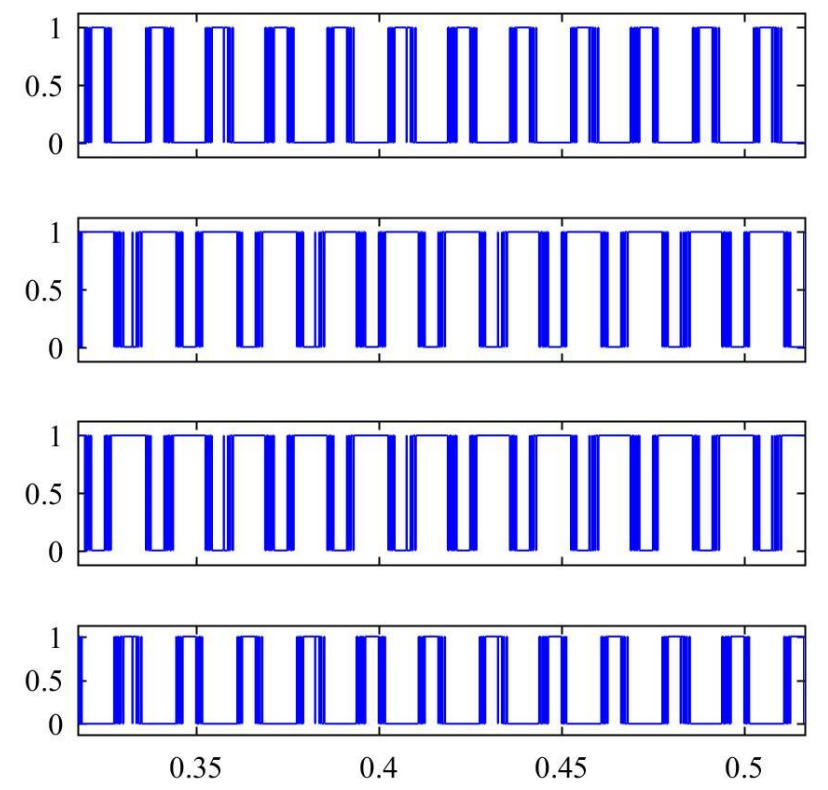

Fig.4. A phase leg switching signals
A phase of grid side converter output is given in Fig. 5. Blue line illustrates no filter of an output phase to phase voltage in Fig.5. Red line illustrates the filter of an output phase to phase voltage.

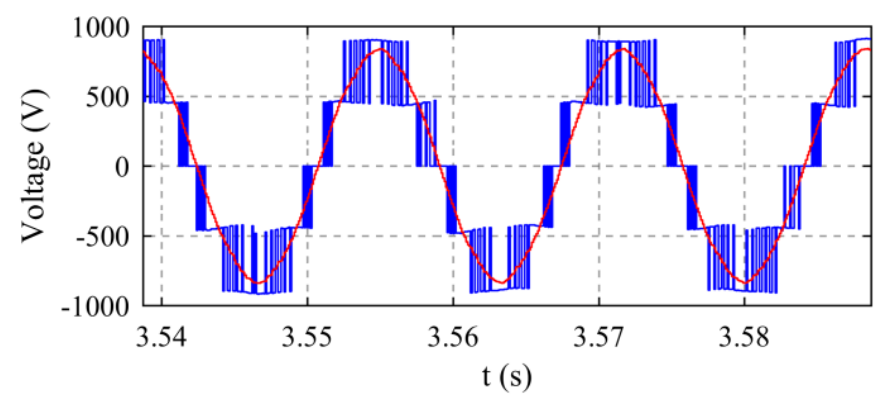

Fig.5. Filter and non-filter of output voltages of the converter

Output voltages of grid side converter are given in Fig. 6. The output voltage values are 1 p.u. The output currents of grid side converter are given in Fig. 7. The output current values are 1 p.u. The simulation tests are realized to confirm the dynamic performance of proposed system. From the current graph in Fig. 8, it is observed that there is no high level of disturbance effect on the signal. The THD value of current of proposed system is $1.76 \%$. Also, this value is below the $5 \%$ limit specified in the IEEE 1547 standard.

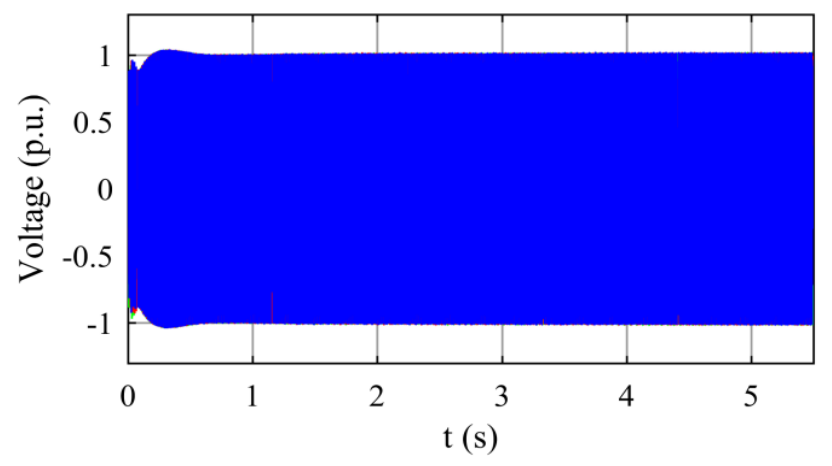

Fig.6. Three phase output voltages of the T-type converter

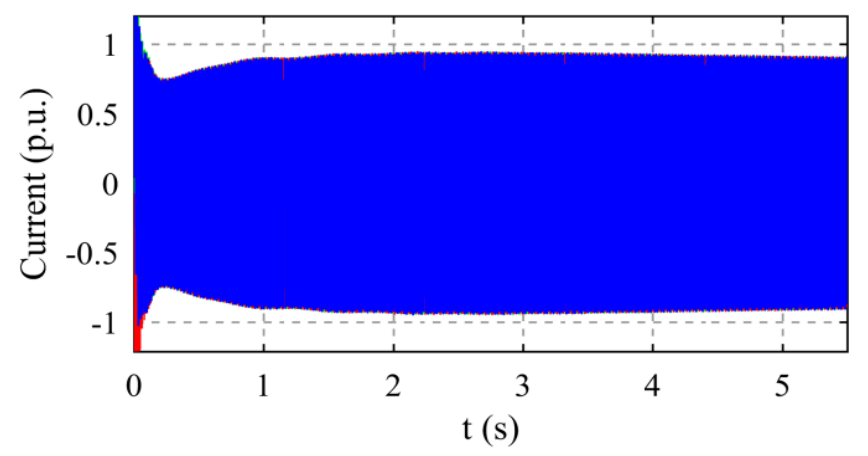

Fig.7. Three phase output currents of the T-type converter 


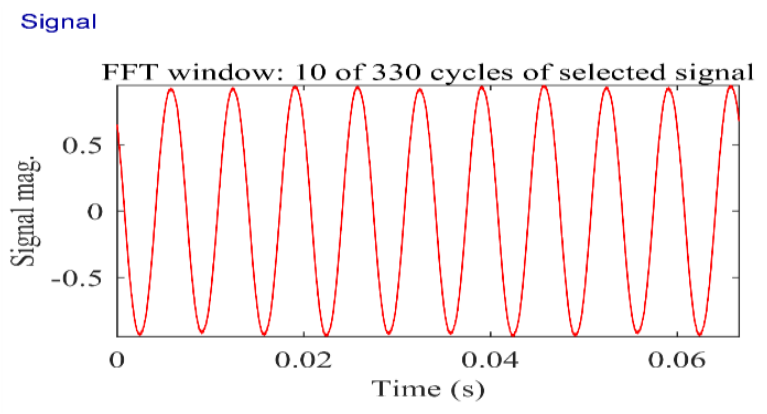

a)

FFT analysis

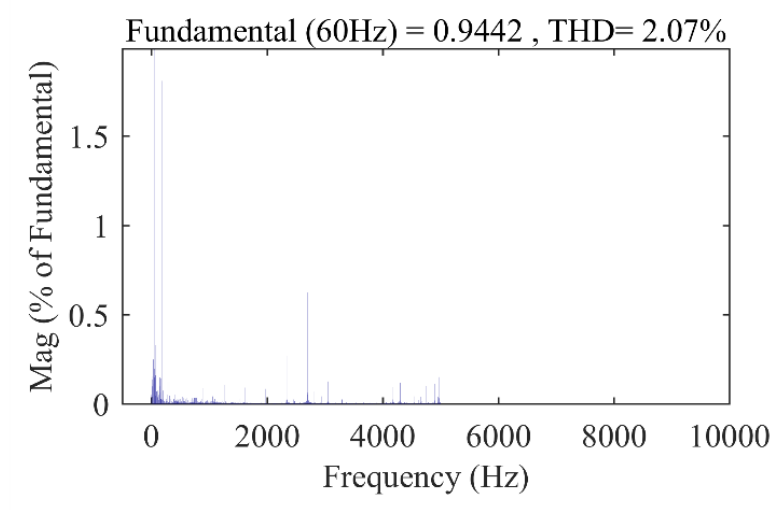

b)

FFT analysis

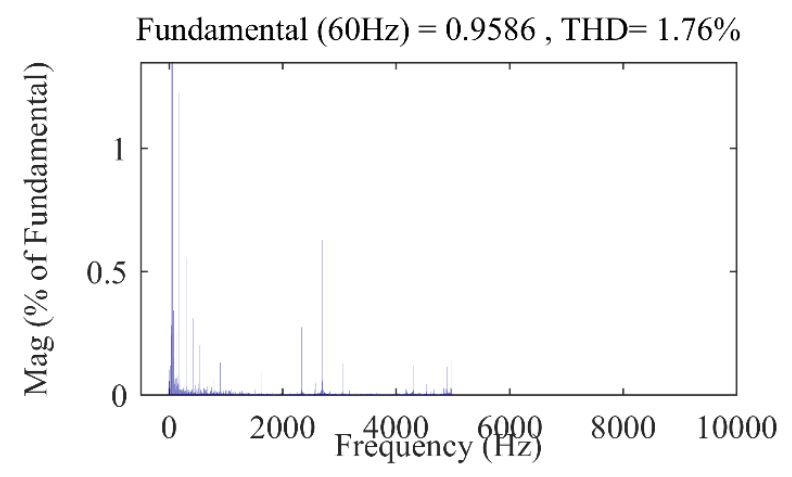

c)

FFT analysis

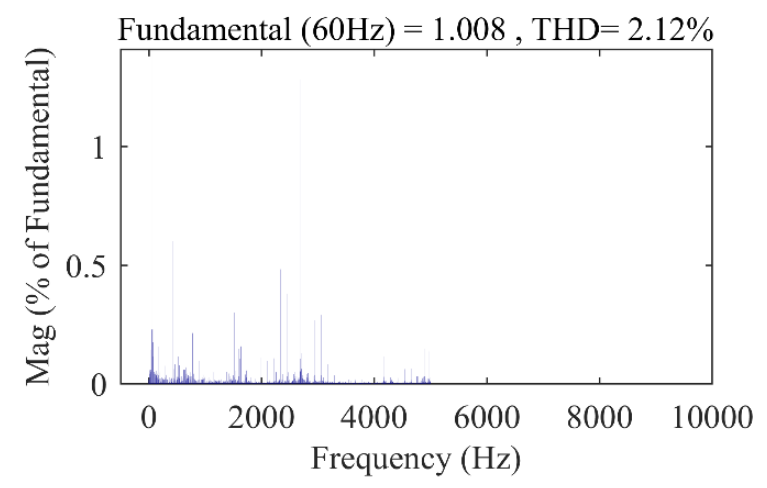

d)
FFT analysis

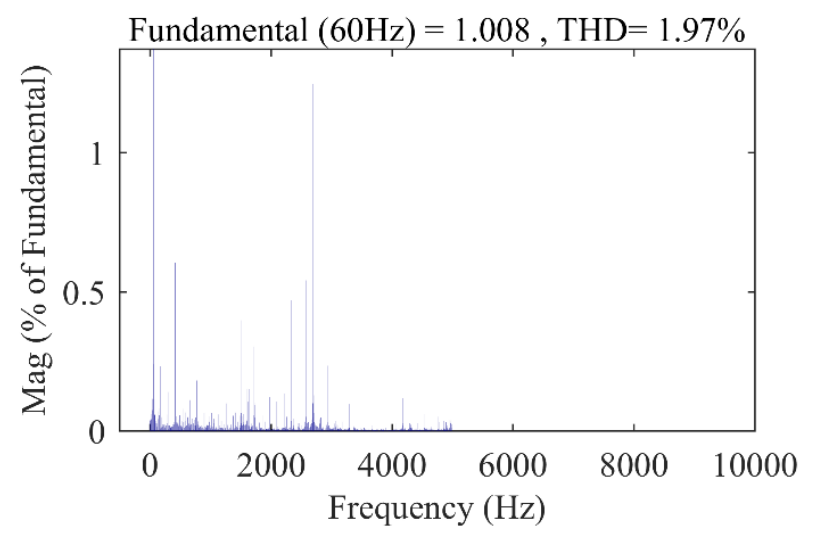

e)

Fig.8. FFT analysis of load current and phase voltage a) signal of current b) THD value of voltage of T-type c) THD value of current of T-type d) THD value of voltage of 3L-NPC e) THD value of current of 3L-NPC

Active power of presented system is illustrated in Fig. 9. The values of active power are $9 \mathrm{MW}$. A voltage (Vdc) of presented system is given in Fig. 10. The value of Vdc is 1150 $\mathrm{V}$. The simulation tests are realized to confirm the dynamic performance of proposed system.

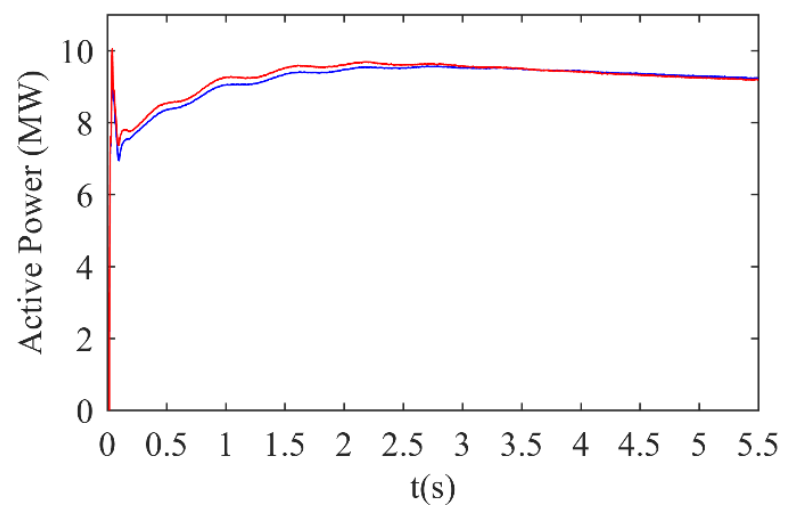

Fig.9. Active Power

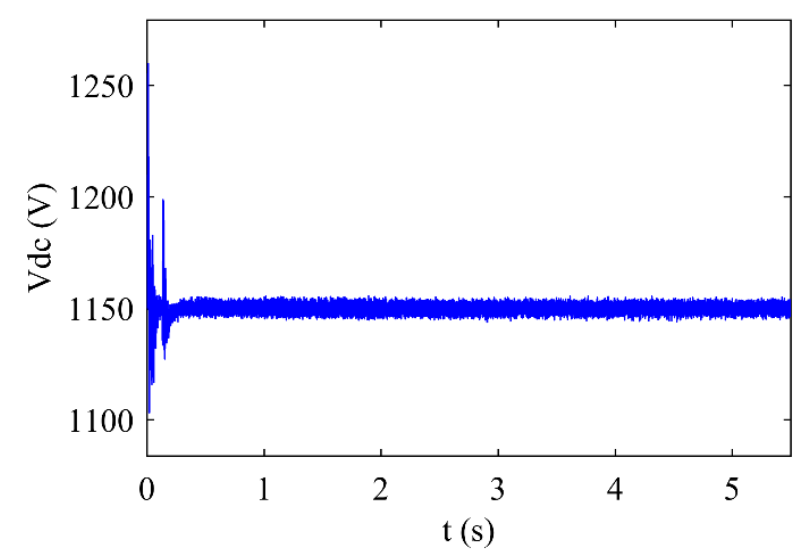

Fig.10. DC link voltage

\section{CONCLUSION}

A three-phase T-type converter topology is presented for wind turbine based on DFIG. The proposed converter system 
is implemented to grid side converter of wind turbine. Fuzzy logic PI controller is applied in the control systems of both converters. THD values of the output voltage and current of the system are measured under same operation conditions. In addition to, DC link and active power values of the system are measured. The DC link voltage value is kept constant at 1150 $\mathrm{V}$. The THD value of the current of the system presented is measured as $1.76 \%$. Also, this value is below the 5\% limit specified in the IEEE 1547 standard. The proposed system are used less electronic components compared to 3L-NPC. Therefore, the proposed system decreases the switching losses and the cost of presented system. The efficiency of proposed converter type has been proven by compared to 3L-NPC converters.

\section{REFERENCES}

[1] S. Bayhan, S. Demirbas and H. Abu-Rub, "Fuzzy-PI-based sensorless frequency and voltage controller for doubly fed induction generator connected to a DC microgrid," in IET Renewable Power Generation, vol. 10, no. 8, pp. 1069-1077, 9 2016, doi: 10.1049/iet-rpg.2015.0504

[2] S. Demirbas, "Self-tuning fuzzy-PI-based current control algorithm for doubly fed induction generator," in IET Renewable Power Generation, vol. 11, no. 13, pp. 1714-1722, 1511 2017, doi: 10.1049/ietrpg.2016.0700.

[3] M. Z. Sujod and I. Erlich, "A new protection scheme for three-level NPC converter based DFIG using zero state control," IEEE PES ISGT Europe 2013, Lyngby, 2013, pp. 1-5, doi: 10.1109/ISGTEurope.2013.6695240.

[4] C. Qin, C. Zhang, A. Chen, X. Xing and G. Zhang, "A Space Vector Modulation Scheme of the Quasi-Z-Source Three-Level T-Type Inverter for Common-Mode Voltage Reduction," in IEEE Transactions on Industrial Electronics, vol. 65, no. 10, pp. 8340-8350, Oct. 2018, doi: 10.1109/TIE.2018.2798611.

[5] M. Schweizer and J. W. Kolar, "Design and Implementation of a Highly Efficient Three-Level T-Type Converter for Low-Voltage Applications," in IEEE Transactions on Power Electronics, vol. 28, no. 2, pp. 899-907, Feb. 2013, doi: 10.1109/TPEL.2012.2203151.

[6] M. Barzegar-Kalashani, B. Tousi, M. A. Mahmud and M. FarhadiKangarlu, "Non-linear integral higher-order sliding mode controller design for islanded operations of T-type three-phase inverter-interfaced distributed energy resources," in IET Generation, Transmission \& Distribution, vol. 14, no. 1, pp. 53-61, 171 2020, doi: 10.1049/ietgtd.2019.0795.

[7] Z. Zhang, A. Anthon and M. A. E. Andersen, "Comprehensive loss evaluation of neutral-point-clamped (NPC) and T-Type three-level inverters based on a circuit level decoupling modulation," 2014 International Power Electronics and Application Conference and Exposition, Shanghai, 2014, pp. 82-87, doi: 10.1109/PEAC.2014.7037833.

[8] S. Tohidi, P. Tavner, R. McMahon, H. Oraee, MR. Zolghadri, S.Shao S, et al. "Low voltage ride-through of DFIG and brushless DFIG: similarities and differences" Electric Power System Research,vol. 110, p.p. $64-72$, 2014. doi: 10.1016/j.epsr.2013.12.018.

[9] R. Celikel "Speed control of BLDC using NARMA-L2 controller in single link manipulator." Balkan Journal of Electrical and Computer Engineering 7.2 (2019): 143-148.

[10] A. Gencer, "Modelling and control of permanent magnet synchronous generator based on three level NPC using fuzzy PI" . Balkan Journal of Electrical and Computer Engineering 6 (2018): 172-177

[11] A. Gencer, "Analysis of Speed/Position Controller Based on Several Types of a Fuzzy Logic for Travelling Wave Ultrasonic Motor," 2019 1st Global Power, Energy and Communication Conference (GPECOM), Nevsehir, Turkey, 2019, pp. 170-174, doi: 10.1109/GPECOM.2019.8778619.

[12] M. R. Tur, M. Wadi, A. Shobole and S. Ay, "Load Frequency Control of Two Area Interconnected Power System Using Fuzzy Logic Control and
PID Controller," 2018 7th International Conference on Renewable Energy Research and Applications (ICRERA), Paris, 2018, pp. 12531258, doi: 10.1109/ICRERA.2018.8566890.

[13] M. Wadi, A. Shobole, M. R. Tur and M. Baysal, "Smart hybrid windsolar street lighting system fuzzy based approach: Case study IstanbulTurkey," 2018 6th International Istanbul Smart Grids and Cities Congress and Fair (ICSG), Istanbul, 2018, pp. 71-75, doi: 10.1109/SGCF.2018.8408945.

[14] Z. Wang, Y. Wu, M. H. Mahmud, Z. Zhao, Y. Zhao and H. A. Mantooth, "Design and Validation of A 250-kW All-Silicon Carbide High-Density Three-Level T-Type Inverter," in IEEE Journal of Emerging and Selected Topics in Power Electronics, vol. 8, no. 1, pp. 578-588, March 2020, doi: 10.1109/JESTPE.2019.2951625.

[15] Semikron "Application Note AN-11001: 3L NPC \& TNPC Topology" http://www.semikron.com, crawled on July 2020

[16] N. Güler ve E. Irmak, "Nötr Kenetlemeli Eviriciler için Çok Giriş - Çok Cıkış̧ı DA-DA Çevirici Tasarımı ve Kontrolü", Gazi Üniversitesi Fen Bilimleri Dergisi Part C: Tasarım ve Teknoloji, c. 7, sayı. 1, ss. 49-62, Mar. 2019, doi:10.29109/gujsc.490144

[17] A. Gündoğdu, R. Çelikel, and Ş. Fidan. "Analysis and Simulation of A Three-Phase Delta Inverter for A Star-Connected RL Load." European Journal of Technique 10.2, 2020, 274-288.

[18] M. Yilmaz, "Real measure of a transmission line data with load fore-cast model for the future." Balkan Journal of Electrical and Computer Engineering 6.2 (2018): 141-145.

[19] Shuhui Li, T. A. Haskew and J. Jackson, "Power generation characteristic study of integrated DFIG and its frequency converter," 2008 IEEE Power and Energy Society General Meeting - Conversion and Delivery of Electrical Energy in the 21st Century, Pittsburgh, PA, 2008, pp. 1-9, doi: 10.1109/PES.2008.4596058.

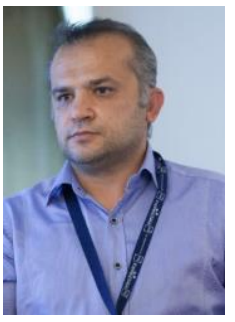

\section{BIOGRAPHY}

ALTAN GENCER was born in 1978. He received the M.Sc. degree of Electrical Education at Technical Education Faculty of Frrat University, 2002. He received Ph. D. degree of Electrical Education at Technical Education Faculty of Gazi University, 2011. From 2014, he is assistant professor by in Department of Electrical and Electronics Engineering, Faculty of Engineering in the Nevsehir H.B.V. University in Turkey. His research interests include of wind farm dynamic modeling, fuzzy logic control system. 